Article

\title{
The Exponentiated Burr XII Power Series Distribution: Properties and Applications
}

\author{
Arslan Nasir ${ }^{1}$, Haitham M. Yousof ${ }^{2}$, Farrukh Jamal ${ }^{1}$ (D) and Mustafa Ç. Korkmaz ${ }^{3, *(D)}$ \\ 1 Department Statistics, The Islamia University, Bahawalpur 63100, Pakistan; \\ arslannasir147@gmail.com (A.N.); drfarrukh1982@gmail.com (F.J.) \\ 2 Department of Statistics, Mathematics and Insurance, Benha University, Benha 13511, Egypt; \\ haitham.yousof@fcom.bu.edu.eg \\ 3 Department of Measurement and Evaluation, Education Faculty, City Campus, Artvin Çoruh University, \\ 08100 Artvin, Turkey \\ * Correspondence: mustafacagataykorkmaz@gmail.com or mcagatay@artvin.edu.tr
}

Received: 30 August 2018; Accepted: 18 December 2018; Published: 21 December 2018

check for updates

\begin{abstract}
In this work, we introduce a new Burr XII power series class of distributions, which is obtained by compounding exponentiated Burr XII and power series distributions and has a strong physical motivation. The new distribution contains several important lifetime models. We derive explicit expressions for the ordinary and incomplete moments and generating functions. We discuss the maximum likelihood estimation of the model parameters. The maximum likelihood estimation procedure is presented. We assess the performance of the maximum likelihood estimators in terms of biases, standard deviations, and mean square of errors by means of two simulation studies. The usefulness of the new model is illustrated by means of three real data sets. The new proposed models provide consistently better fits than other competitive models for these data sets.
\end{abstract}

Keywords: Burr distribution; compounding; hazard rate; lifetime distribution; maximum likelihood method; power series distribution

\section{Introduction and Motivation}

Burr XII distribution is the most commonly used distribution for non-monotonic hazard rates. Burr XII distribution has algebraic tails useful for modeling failures that occur with lesser frequency than those with corresponding models based on exponential tails. Burr XII distribution finds its application in flood frequency, software reliability, structural and wind engineering. Burr XII distribution has two popular distributions as sub models i.e., Lomax distribution and Log logistic distributions. Weibull distribution is a limiting case of Burr XII distribution. Many extensions of the Burr XII distribution are found in literature, such as Kumaraswamy Burr XII distribution by [1], extended Marshall Olkin Burr XII distribution by [2], McDonald Burr XII distribution by [3] and a new generalized Burr family of distributions is proposed by [4].

The cumulative distribution function (cdf) and probability density function (pdf) of the two parameter Burr XII (BXII) distribution are given by

$$
F_{c, k}(x)=1-\left(1+x^{c}\right)^{-k}, x>0, c, k>0
$$

and

$$
f_{c, k}(x)=c k x^{c-1}\left(1+x^{c}\right)^{-k-1}
$$

If $c=1$, the scaled BXII distribution reduces to Lomax distribution, if $k=1$, then Burr XII distribution reduces to $\log$ logistic distribution (see [5]). Furthermore, Burr XII distribution finds 
its application in various areas such as flood frequency, software reliability, structural engineering, wind engineering, renewable energy and climatology (see Garcia et al. [6]; Harris [7], Kantar and Usta [8]; Carta et al. [9]; Panteli and Mancarella [10]; Chiodo and De Falco [11]; Feijóo [12]). On the other hand, Noack [13] proposed and studied the power series class of distributions; this class of distribution includes binomial, geometric, logarithmic and Poisson distributions as special cases. However, these distributions may not be useful when a random variable (rv) takes the value of zero with high probability i.e., zero inflated. In such situations, it is more appropriate to consider the distribution which is truncated at zero.

The cdf of the G-power series (G-PS) distributions is

$$
F_{\lambda, \xi}(x)=1-C[\lambda \bar{G}(x ; \xi)] / C(\lambda) .
$$

A discrete rv $N$ is a member of power series distributions (truncated at the zero), if the probability mass function (pmf) is given by

$$
P(N=n \mid \lambda)=a_{n} \lambda^{n} /\left.C(\lambda)\right|_{(n=1,2, \ldots)},
$$

where $a_{n} \geq 0, C(\lambda)=\sum_{n=1}^{\infty} a_{n} \lambda^{n}$ and $\lambda \in(0, s)$ is chosen such that $C(\lambda)$ is finite and its first, second and third derivative are defined also

$$
C^{\prime}(\lambda)=\sum_{n=1}^{\infty} n a_{n} \lambda^{n-1}
$$

Some example of $C(\lambda)$ functions are given by Table 1 . The pdf, survival function (sf) and hazard rate function (hrf) corresponding to Equation (3) are

$$
\begin{gathered}
f_{\lambda, \xi}(x)=\lambda g(x) C^{\prime}[\lambda \bar{G}(x ; \xi)] / C(\lambda), \\
\bar{F}_{\lambda, \xi}(x)=C[\lambda \bar{G}(x ; \xi)] / C(\lambda),
\end{gathered}
$$

and

$$
h_{\lambda, \xi}(x)=\lambda g(x ; \xi) C^{\prime}[\lambda \bar{G}(x ; \xi)] / C[\lambda \bar{G}(x ; \xi)] .
$$

The quantile function can be obtained by using Lambert function.

Table 1. Useful quantities for power series distributions.

\begin{tabular}{ccccc}
\hline Distribution & $\boldsymbol{C}(\lambda)$ & $\boldsymbol{C}^{-\mathbf{1}}(\lambda)$ & $\boldsymbol{a}_{\boldsymbol{n}}$ & Parameter Space \\
\hline Poisson & $e^{\lambda}-1$ & $\log (1+\lambda)$ & $(n !)^{-1}$ & $(0, \infty)$ \\
Geometric & $\lambda(1-\lambda)^{-1}$ & $\lambda(1+\lambda)^{-1}$ & 1 & $(0,1)$ \\
Binomial & $(1+\lambda)^{m}-1$ & $(\lambda+1)^{m^{1}}-1$ & $\left(\begin{array}{c}n \\
m\end{array}\right)$ & $(0, \infty)$ \\
Logarithmic & $-\log (1-\lambda)$ & $1-e^{-\lambda}$ & $n^{-1}$ & $(0,1)$ \\
\hline
\end{tabular}

We provide three motivations of the G-PS class of distribution, which can be applied in some interesting situation: due to the Stochastic reorientation

$$
Z=\min \left(X_{1}, X_{2}, \ldots, Z_{N}\right),
$$

the G-PS class of distributions can arise in many industrial applications and biological organisms. The G-PS class of distributions can be used to model approximately the time to the first failure of a system of identical components that are in a series. The G-PS class of distributions exhibit some interesting behaviors with non-monotonic failure rates such as bathtub, upside bathtub and increasing-decreasing failure rates which are more likely to be encountered in real life situations. 
The justification for the practicality of the new model is based on the wider use of the BXII model. In addition, we are motivated to introduce the exponentiated Burr XII power series (EBXIIPS) model because it exhibits increasing, decreasing, bathtub and reversed J shaped hazard rates as illustrated in Figures 1-4. It can be viewed as a suitable model for fitting the right skewed and unimodal data.

The rest of the paper is outlined as follows. Construction of the new family is given in Section 2. Four special models of the new family are presented in Section 3. In Section 4, we derive some mathematical properties of this family. Maximum likelihood estimation of the parameters is addressed in Section 5. Two simulation studies are given by Section 6 to see performance of the maximum likelihood estimators for two special members of this family. In Section 7, the potentiality of the proposed models is illustrated by means of two real data sets. In Section 8, we offer some concluding remarks.

\section{Construction of the New Family}

Let $X_{(1)}=\min \left(X_{1}, X_{2}, \ldots, X_{n}\right)$. The conditional cdf of $X_{(1)} \mid N=n$ is given by

$$
G_{X_{(1)} \mid N=n}(x)=1-[\bar{G}(x)]^{n} .
$$

If $\bar{G}($.$) is the survival function of exponentiated Burr XII (EBXII) distribution, with cdf and$ pdf as under

$$
G_{c, k, \alpha}(x)=\left.\left[1-\left(1+x^{c}\right)^{-k}\right]^{\alpha}\right|_{(x>0, c, k, \alpha>0)},
$$

and

$$
g_{c, k, \alpha}(x)=\alpha c k x^{c-1}\left(1+x^{c}\right)^{-k-1}\left[1-\left(1+x^{c}\right)^{-k}\right]^{\alpha-1} .
$$

Then, Equation (8) becomes

$$
G_{X_{(1)} \mid N=n}(x)=1-\left[1-\left[1-\left(1+x^{c}\right)^{-k}\right]^{\alpha}\right]^{n} .
$$

Then, the cdf and pdf of the EBXIIPS distribution are, respectively, given by

$$
F_{\Theta}(x)=1-C\left[\lambda-\lambda\left[1-\left(1+x^{c}\right)^{-k}\right]^{\alpha}\right] / C(\lambda),
$$

and

$$
f_{\boldsymbol{\Theta}}(x)=\lambda \alpha c k x^{c-1} \frac{\left[1-\left(1+x^{c}\right)^{-k}\right]^{\alpha-1}}{\left(1+x^{c}\right)^{k+1}} \frac{C^{\prime}\left[\lambda-\lambda\left[1-\left(1+x^{c}\right)^{-k}\right]^{\alpha}\right]}{C(\lambda)},
$$

where $\boldsymbol{\Theta}=(\lambda, c, k, \alpha)^{T}$. For $\alpha=1$, the EBXIIPS family is reduced to a Burr XII power series family that has been introduced by [14]. The hrf of EBXIIPS distribution is obtained with

$$
h_{\Theta}(x)=\lambda \alpha c k x^{c-1} \frac{\left[1-\left(1+x^{c}\right)^{-k}\right]^{\alpha-1}}{\left(1+x^{c}\right)^{k+1}} \frac{C^{\prime}\left[\lambda-\lambda\left[1-\left(1+x^{c}\right)^{-k}\right]^{\alpha}\right]}{C\left[\lambda-\lambda\left[1-\left(1+x^{c}\right)^{-k}\right]^{\alpha}\right]} .
$$

The quantile function of EBXIIPS distribution, $Q_{x}(p)$, can be defined as $F\left(Q_{x}(p)\right)=p$

$$
x=Q_{x}(p)=\left\{-1+[1-Z(\lambda, p)]^{-\frac{1}{k}}\right\}^{\frac{1}{c}},
$$

where

$$
Z(\lambda, p)=\left\{\frac{\lambda-C^{-1}[(1-p) C(\lambda)]}{\lambda}\right\}^{\frac{1}{\alpha}}
$$


and $C^{-1}($.$) is the inverse function of C($.$) .$

Proposition 1. The exponentiated Burr XII distribution is the limiting case of the EBXIIPS family of distributions when $\lambda \rightarrow 0^{+}$.

Proof. For $X>0$, we have

$$
\begin{aligned}
\lim _{\lambda \rightarrow 0^{+}} F(x) & =1-\lim _{\lambda \rightarrow 0^{+}} \frac{\sum_{n=1}^{\infty} a_{n}\left[\lambda\left\{1-\left[1-\left(1+x^{c}\right)^{-k}\right]^{\alpha}\right\}\right]^{n}}{\sum_{n=1}^{\infty} a_{n} \lambda^{n}} \\
& =1-\lim _{\lambda \rightarrow 0^{+}} \frac{a_{1} \lambda\left\{1-\left[1-\left(1+x^{c}\right)^{-k}\right]^{\alpha}\right\}+\sum_{n=2}^{\infty} a_{n}\left[\lambda\left\{1-\left[1-\left(1+x^{c}\right)^{-k}\right]^{\alpha}\right\}\right]^{n}}{a_{1} \lambda+\sum_{n=2}^{\infty} a_{n} \lambda^{n}} \\
& =1-\lim _{\lambda \rightarrow 0^{+}} \frac{a_{1} \lambda\left[\left\{1-\left[1-\left(1+x^{c}\right)^{-k}\right]^{\alpha}\right\}+a_{1}^{-1} \sum_{n=2}^{\infty} a_{n} \lambda^{n-1}\left\{1-\left[1-\left(1+x^{c}\right)^{-k}\right]^{\alpha}\right\}\right]^{n}}{a_{1} \lambda\left[1+a_{1}^{-1} \sum_{n=2}^{\infty} a_{n} \lambda^{n}\right]} .
\end{aligned}
$$

Now, applying the limit on the right side, we have

$$
\lim _{\lambda \rightarrow 0^{+}} F(x)=\left[1-\left(1+x^{c}\right)^{-k}\right]^{\alpha} .
$$

Proposition 2. The infinite mixture representation of EBXIIPS can be expressed in terms of EBXII distribution with parameters $c, k$ and $n \alpha$.

Proof. The pdf of EBXIIPS distribution can be expressed as an infinite mixture representation of order distribution i.e.,

$$
f(x)=\sum_{n=1}^{\infty} P(N=n) g_{(1)}(x ; n),
$$

where $P(N=n)$ is defined in (4). Now, (17) becomes

$$
f(x)=\sum_{n=1}^{\infty} \frac{a_{n} \lambda^{n}}{C(\lambda)} g_{(1)}(x ; n),
$$

where $g_{(1)}(x ; n)$ is the pdf of $Y_{(i)}=\min \left(Y_{1}, \ldots, Y_{n}\right)$, is given by

$$
g_{(1)}(x ; n)=n g(x)[1-G(x)]^{n} .
$$

Using (9) and (10), we have

$$
g_{(1)}(x ; n)=n \alpha c k \frac{x^{c-1}}{\left(1+x^{c}\right)^{k+1}}[1-G(x)]^{n}\left[1-\left(1+x^{c}\right)^{-k}\right]^{n \alpha-1} .
$$

Now, (21) becomes

$$
f(x)=n \alpha c k \sum_{n=1}^{\infty} \frac{a_{n} \lambda^{n}}{C(\lambda)} \frac{x^{c-1}}{\left(1+x^{c}\right)^{k+1}}[1-G(x)]^{n}\left[1-\left(1+x^{c}\right)^{-k}\right]^{n \alpha-1}=\sum_{n=1}^{\infty} w_{n} g(x ; c, k, n \alpha),
$$

where $w_{n}=n \alpha c k \frac{a_{n} \lambda^{n}}{C(\lambda)}$ and $g(x ; c, k, n \alpha)=\frac{x^{c-1}}{\left(1+x^{c}\right)^{k+1}}[1-G(x)]^{n}\left[1-\left(1+x^{c}\right)^{-k}\right]^{n \alpha-1}$ is the EBXII density function with parameters $c, k$ and $n \alpha$. 


\section{Special Sub Models}

In this section, we will discuss some special models of the power series distributions such as logarithmic, binomial, Poisson and geometric distributions.

\subsection{EBXII Logarithmic Distribution}

Consider the logarithmic distribution to be the zero truncated power series distribution with $a_{n}=\frac{1}{n}$ and $C(\theta)=-\log (1-\theta)$. Then, the cdf and pdf and hrf of EBXII logarithmic (EBXII-L) distribution are respectively given by

$$
\begin{gathered}
F_{\theta, c, k, \alpha}(x)=1-\frac{\log \left[1-\theta+\theta\left\{1-\left(1+x^{c}\right)^{-k}\right\}^{\alpha}\right]}{\log (1-\theta)}, \\
f_{\theta, c, k, \alpha}(x)=\frac{\theta \alpha c k x^{c-1}\left(1+x^{c}\right)^{-k-1}\left[1-\left(1+x^{c}\right)^{-k}\right]^{\alpha-1}}{\log (1-\theta)\left\{\theta-\theta\left[1-\left(1+x^{c}\right)^{-k}\right]^{\alpha}-1\right\}},
\end{gathered}
$$

and

$$
h_{\theta, c, k, \alpha}(x)=\frac{\theta \alpha c k x^{c-1}\left(1+x^{c}\right)^{-k-1}\left[1-\left(1+x^{c}\right)^{-k}\right]^{\alpha-1}}{\left\{\theta-\theta\left[1-\left(1+x^{c}\right)^{-k}\right]^{\alpha}-1\right\} \log \left\{1-\theta+\theta\left[1-\left(1+x^{c}\right)^{-k}\right]^{\alpha}\right\}} .
$$

For the EBXII-L model, we can say that $\theta$ parameter is also valid on $(-\infty, 1)$. In Figure 1 , the plots of density and hazard rate functions are displayed. The density is right skewed, reversed J and symmetrical, while hrf is decreasing and upside-down bathtub.
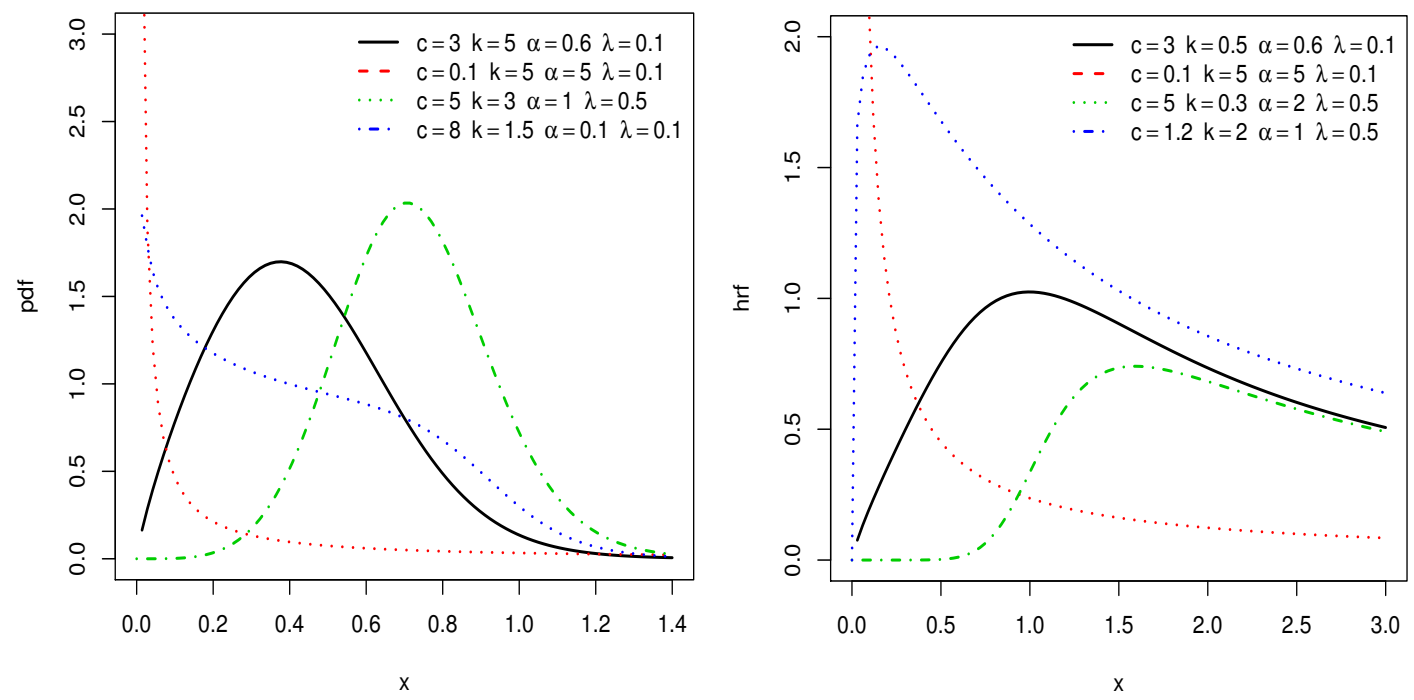

Figure 1. Plots of pdf and hrf for EBXII-L distribution with different parameter values.

\subsection{EBXII Binomial Distribution}

Consider the binomial distribution to be the zero truncated power series distribution with $a_{n}=\left(\begin{array}{c}m \\ n\end{array}\right)$ and $C(\theta)=(\theta+1)^{m}-1$, where $m(n \leq m)$ is the number of replicas. Then, the cdf and pdf and hrf of EBXII binomial (EBXII-B) distribution are respectively given by

$$
F_{\theta, c, k, \alpha}(x)=1-\frac{-1+\left\{1+\theta-\theta\left[1-\left(1+x^{c}\right)^{-k}\right]^{\alpha}\right\}^{m}}{-1+(\theta+1)^{m}},
$$




$$
\begin{aligned}
f_{\theta, c, k, \alpha}(x)= & m \theta \alpha c k x^{c-1}\left(1+x^{c}\right)^{-k-1}\left[1-\left(1+x^{c}\right)^{-k}\right]^{\alpha-1} \\
& \times \frac{\left\{1+\theta-\theta\left[1-\left(1+x^{c}\right)^{-k}\right]^{\alpha}\right\}^{m-1}}{-1+(\theta+1)^{m}}
\end{aligned}
$$

and

$$
\begin{aligned}
h_{\theta, c, k, \alpha}(x)= & m \theta \alpha c k x^{c-1}\left(1+x^{c}\right)^{-k-1}\left\{1-\left(1+x^{c}\right)^{-k}\right\}^{\alpha-1} \\
& \times \frac{\left\{1+\theta-\theta\left[1-\left(1+x^{c}\right)^{-k}\right]^{\alpha}\right\}^{m-1}}{\left\{1+\theta-\theta\left[1-\left(1+x^{c}\right)^{-k}\right]^{\alpha}\right\}^{m}-1} .
\end{aligned}
$$

In Figure 2, the plots of density and hazard rate functions are displayed. The density is right skewed and reversed J, while hrf is decreasing and upside-down bathtub.
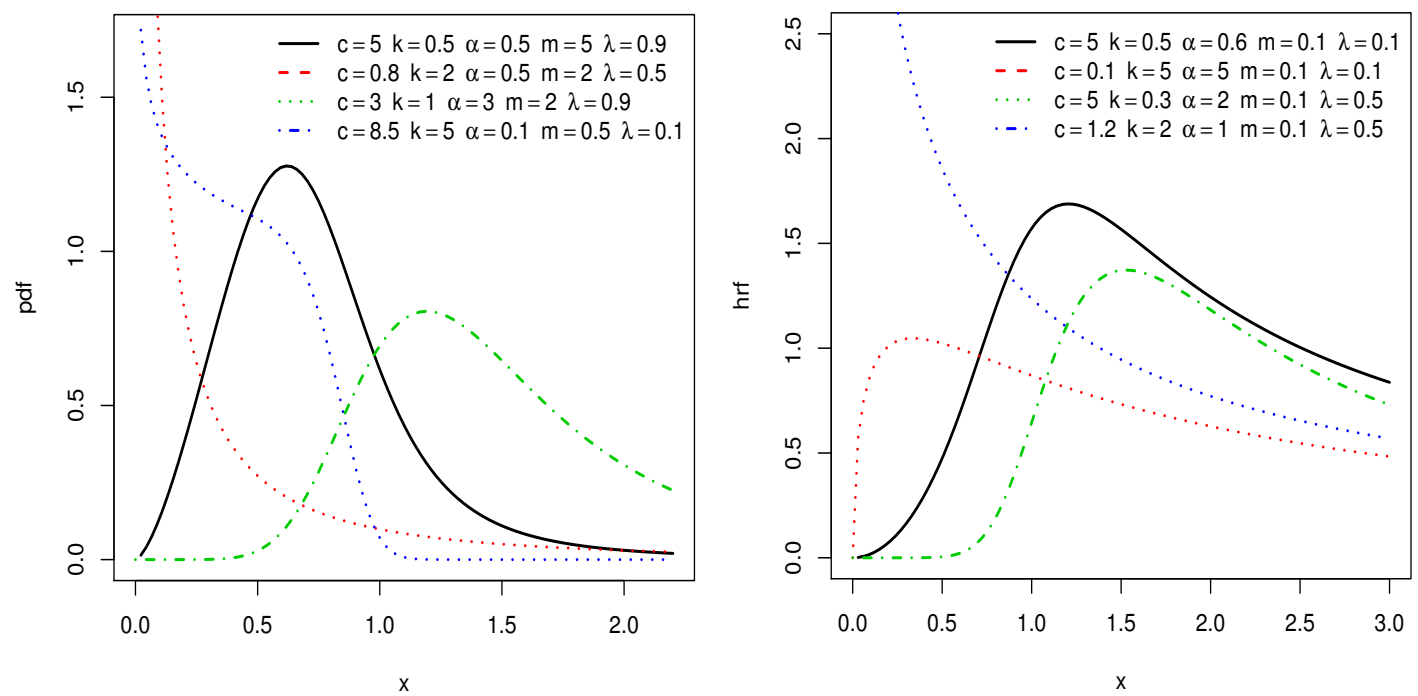

Figure 2. Plots of pdf and hrf for EBXII-B distribution with different parameter values.

\subsection{EBXII Poisson Distribution}

Consider the Poisson distribution to be the zero truncated power series distribution with $a_{n}=\frac{1}{n !}$ and $C(\theta)=e^{\theta}-1$. Then, the cdf and pdf and hrf of EBXII Poisson (EBXII-P) distribution are respectively given by

$$
\begin{gathered}
F_{\theta, c, k, \alpha}(x)=\frac{e^{\theta}-e^{\theta-\theta\left[1-\left(1+x^{c}\right)^{-k}\right]^{\alpha}}}{e^{\theta}-1}, \\
f_{\theta, c, k, \alpha}(x)=\frac{\theta \alpha c k x^{c-1}\left[1-\left(1+x^{c}\right)^{-k}\right]^{\alpha-1} e^{\theta-\theta\left[1-\left(1+x^{c}\right)^{-k}\right]^{\alpha}}}{\left(1+x^{c}\right)^{k+1}\left(e^{\theta}-1\right)},
\end{gathered}
$$

and

$$
h_{\theta, c, k, \alpha}(x)=\theta \alpha c k x^{c-1}\left[1-\left(1+x^{c}\right)^{-k}\right]^{\alpha-1} \frac{e^{\theta-\theta\left[1-\left(1+x^{c}\right)^{-k}\right]^{\alpha}}}{e^{\theta-\theta\left[1-\left(1+x^{c}\right)^{-k}\right]^{\alpha}-1} .}
$$

We note that EBXII-P distribution has been introduced by [15]. In Figure 3, the plots of density and hazard rate functions are displayed. The density is reversed J, symmetrical and left skewed, while hrf is decreasing, increasing and bathtub shaped. 

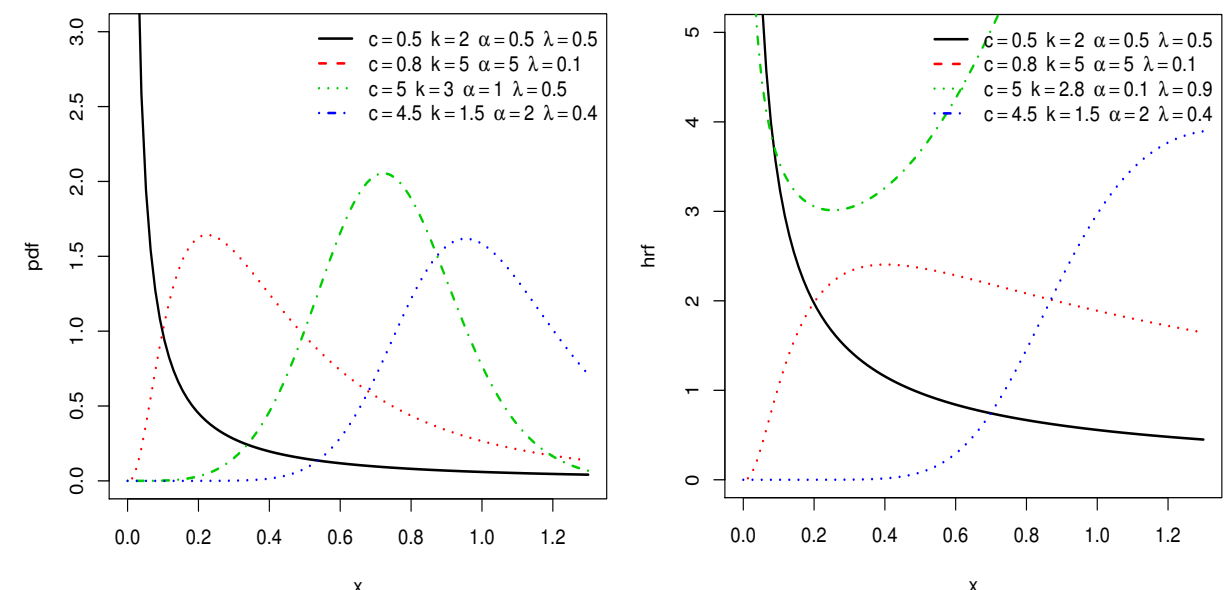

Figure 3. Plots of pdf and hrf for EBXII-P distribution with different parameter values.

\subsection{EBXII Geometric Distribution}

Consider the geometric distribution to be the zero truncated power series distribution with $a_{n}=1$ and $C(\theta)=\frac{\theta}{1-\theta}$. Then, the cdf and pdf and hrf of EBXII geometric (EBXII-G) distribution are respectively given by

$$
\begin{gathered}
F_{\theta, c, k, \alpha}(x)=\frac{\left[1-\left(1+x^{c}\right)^{-k}\right]^{\alpha}}{1-\theta+\theta\left[1-\left(1+x^{c}\right)^{-k}\right]^{\alpha}}, \\
f_{\theta, c, k, \alpha}(x)=\frac{\alpha c k(1-\theta) x^{c-1}\left[1-\left(1+x^{c}\right)^{-k}\right]^{\alpha-1}}{\left\{1-\theta+\theta\left[1-\left(1+x^{c}\right)^{-k}\right]^{\alpha}\right\}^{2}}
\end{gathered}
$$

and

$$
h_{\theta, c, k, \alpha}(x)=\frac{\alpha c k x^{c-1}\left[1-\left(1+x^{c}\right)^{-k}\right]^{\alpha-1}}{\left\{1-\left[1-\left(1+x^{c}\right)^{-k}\right]^{\alpha}\right\}\left\{1-\theta+\theta\left[1-\left(1+x^{c}\right)^{-k}\right]^{\alpha}\right\}} .
$$

For the EBXII-G model, we can say that $\theta$ parameter is also valid on $(-\infty, 1)$. In Figure 4 , the plots of density and hrfs are displayed. The density is reversed J, symmetrical and right skewed, while hrf is decreasing, bathtub and upside-down bathtub.
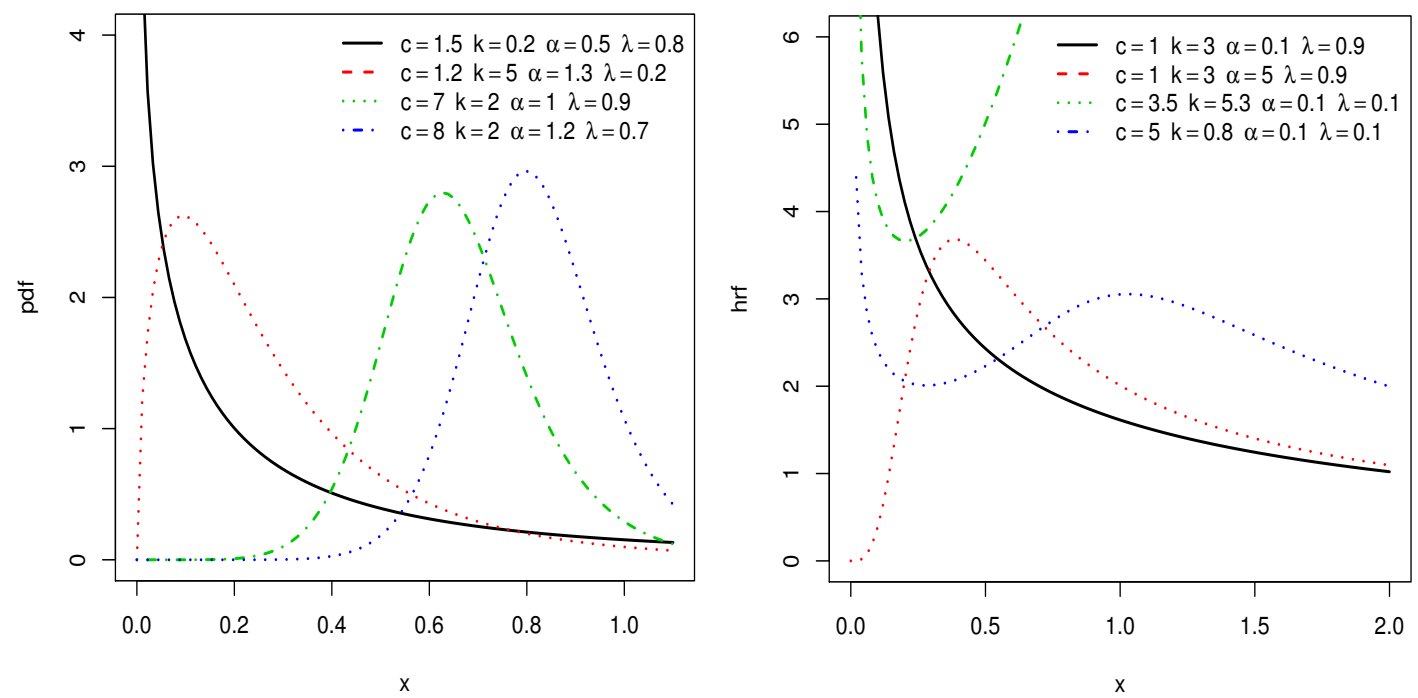

Figure 4. Plots of pdf and hrf for EBXII-G distribution with different parameter values. 


\section{Mathematical Properties}

\section{Moments}

The $r^{\text {th }}$ moments of EBPS distribution can be obtained by using the following expressions:

$$
\mu_{r}^{\prime}=\int_{0}^{\infty} x^{r} f(x) d x
$$

Using the infinite mixture representation in (21), we have

$$
\mu_{r}^{\prime}=\sum_{n=1}^{\infty} w_{n} \int_{0}^{\infty} x^{r} g(x ; c, k, n \alpha) d x=\sum_{n=1}^{\infty} w_{n}\left(\left.\tau_{r}\right|_{0} ^{\infty}\right),
$$

where $\left.\tau_{r}\right|_{0} ^{\infty}=\int_{0}^{\infty} x^{r} g(x ; c, k, n \alpha) d x$. Consider

$$
\left.\tau_{r}\right|_{0} ^{\infty}=\int_{0}^{\infty} x^{r+c-1} \frac{\left[\left(1+x^{c}\right)^{k}\right]^{n \alpha-1}}{\left(1+x^{c}\right)^{k+1}} d x
$$

Using the generalized binomial theorem and, after some algebra, we have

$$
\left.\tau_{r}\right|_{0} ^{\infty}=\sum_{j=0}^{\infty}\left(\begin{array}{c}
n \alpha-1 \\
j
\end{array}\right)(-1)^{j} B\left(1+\frac{r}{c},(1+j) k-\frac{r}{c}\right),
$$

where $B(\cdot, \cdot)$ is the ordinary beta function. Similarly, the $\mathrm{r}^{\text {th }}$ incomplete moment is

$$
T_{r}^{\prime}(x)=\sum_{n=1}^{\infty} w_{n} \int_{0}^{\infty} x^{r} g(x ; c, k, n \alpha) d x=\sum_{n=1}^{\infty} w_{n} \Delta_{r}^{\prime}(X),
$$

where

$$
\Delta_{r}^{\prime}(X)=\sum_{j=0}^{\infty}\left(\begin{array}{c}
n \alpha-1 \\
j
\end{array}\right)(-1)^{j} B_{x^{c}}\left(1+\frac{r}{c},(1+j) k-\frac{r}{c}\right)
$$

and $B_{z}(\cdot, \cdot)$ is the incomplete beta function. The moment generating function of EBPS distribution can be obtained as

$$
M_{0}(t)=\sum_{n=1}^{\infty} w_{n} \int_{0}^{\infty} e^{t x} g(x ; c, k, n \alpha) d x=\sum_{n=1}^{\infty} w_{n} M_{E B}(t),
$$

where

$$
M_{E B}(t)=\int_{0}^{\infty} e^{t x} \frac{x^{c-1}}{\left(1+x^{c}\right)^{k+1}}\left[\left(1+x^{c}\right)^{k}\right]^{n \alpha-1} d x .
$$

Using generalize binomial theorem and after some algebra, we have

$$
M_{E B}(t)=\sum_{j=0}^{\infty} \sum_{i=0}^{\infty}\left(\begin{array}{c}
n \alpha-1 \\
j
\end{array}\right)\left(\begin{array}{c}
(1+j) k+i \\
i
\end{array}\right)(-1)^{i+j} \Gamma((1+i) c)\left(\frac{-1}{t}\right)^{(1+i) c}
$$

The mean deviations about mean and median of EBPS distribution can be obtained as

$$
D_{\mu}=2 \mu F(\mu)-2 T_{1}^{\prime}(\mu)
$$


and

$$
D_{M}=\mu-2 T_{1}^{\prime}(M)
$$

where $\mu=E(x)=\mu_{1}^{\prime}$ can be obtained from (12), $F($.$) can be obtained from (15) and T_{1}^{\prime}(z)$ is the first incomplete moment.

\section{Estimation}

The maximum likelihood estimators (MLEs) has a desirable properties and can be used for constructing confidence intervals and regions and also in test statistics. The normal approximation for these estimators in large samples can be easily handled either analytically or numerically. Thus, we consider the estimation of the unknown parameters of this family from complete samples only by maximum likelihood. Let $x_{1}, \ldots, x_{n}$ be a random sample from the EBXIIPS distribution with parameters $\lambda, \alpha, k$ and $c$. Let $\boldsymbol{\Theta}=(\lambda, \alpha, k, c)^{T}$ be the $4 \times 1$ parameter vector. For determining the MLE of parameters, we have the log-likelihood function

$$
\begin{aligned}
\ell=\ell(\boldsymbol{\Theta}) & =n \log c+n \log \lambda+n \log k+n \log \alpha-n \log C[\lambda]+(c-1) \sum_{i=1}^{n} \log x_{i}-(k+1) \sum_{i=1}^{n} \log \left(1+x_{i}^{c}\right) \\
& +(n \alpha-1) \sum_{i=1}^{n} \log \left[1-\left(1+x_{i}^{c}\right)^{-k}\right]+\log \left(C^{\prime}\left\{\lambda-\lambda\left[1-\left(1+x_{i}^{c}\right)^{-k}\right]^{\alpha}\right\}\right) .
\end{aligned}
$$

The components of score vector are

$$
\begin{aligned}
U_{\lambda}= & \frac{n}{\lambda}-\frac{n C^{\prime}[\lambda]}{C[\lambda]}+\sum_{i=1}^{n} \frac{\left[1-\left(1+x_{i}^{c}\right)^{-k}\right]^{\alpha} C^{\prime \prime}\left\{\lambda-\lambda\left[1-\left(1+x_{i}^{c}\right)^{-k}\right]^{\alpha}\right\}}{C^{\prime}\left\{\lambda-\lambda\left[1-\left(1+x_{i}^{c}\right)^{-k}\right]^{\alpha}\right\}}, \\
U_{\alpha}= & \frac{n}{\alpha}-\lambda \sum_{i=1}^{n} \frac{\log \left[1-\left(1+x_{i}^{c}\right)^{-k}\right]\left[1-\left(1+x_{i}^{c}\right)^{-k}\right]^{\alpha} C^{\prime \prime}\left\{\lambda-\lambda\left[1-\left(1+x_{i}^{c}\right)^{-k}\right]^{\alpha}\right\}}{C^{\prime}\left\{\lambda-\lambda\left[1-\left(1+x_{i}^{c}\right)^{-k}\right]^{\alpha}\right\}} \\
& +n \sum_{i=1}^{n} \log \left[1-\left(1+x_{i}^{c}\right)^{-k}\right], \\
U_{k}= & \frac{n}{k}-\sum_{i=1}^{n} \log \left(1+x_{i}^{c}\right)+(n \alpha-1) \sum_{i=1}^{n} \frac{\log \left(1+x_{i}^{c}\right)\left(1+x_{i}^{c}\right)^{-k}}{1-\left(1+x_{i}^{c}\right)^{-k}} \\
& -\alpha \lambda \sum_{i=1}^{n} \frac{\log \left(1+x_{i}^{c}\right)\left(1+x_{i}^{c}\right)^{-k}\left[1-\left(1+x_{i}^{c}\right)^{-k}\right]^{\alpha-1} C^{\prime \prime}\left\{\lambda-\lambda\left[1-\left(1+x_{i}^{c}\right)^{-k}\right]^{\alpha}\right\}}{C^{\prime}\left\{\lambda-\lambda\left[1-\left(1+x_{i}^{c}\right)^{-k}\right]^{\alpha}\right\}}
\end{aligned}
$$

and

$$
\begin{aligned}
U_{c}= & \frac{n}{c}-\sum_{i=1}^{n} \log x_{i}-(k+1) \sum_{i=1}^{n} \frac{x_{i}^{c} \log x_{i}}{1+x_{i}^{c}}+k(n \alpha-1) \sum_{i=1}^{n} \frac{x_{i}^{c} \log x_{i}\left(1+x_{i}^{c}\right)^{-k-1}}{-\left(1+x_{i}^{c}\right)^{-k} 1} \\
& -k \alpha \sum_{i=1}^{n} \frac{x_{i}^{c} \log x_{i}\left(1+x_{i}^{c}\right)^{-k-1}\left[1-\left(1+x_{i}^{c}\right)^{-k}\right]^{\alpha-1} C^{\prime \prime}\left\{\lambda-\lambda\left[1-\left(1+x_{i}^{c}\right)^{-k}\right]^{\alpha}\right\}}{C^{\prime}\left\{\lambda-\lambda\left[1-\left(1+x_{i}^{c}\right)^{-k}\right]^{\alpha}\right\}} .
\end{aligned}
$$

Setting the nonlinear system of equations $U_{\lambda}=U_{\alpha}=U_{k}=U_{c}=0$ above and solving them simultaneously yields the MLE $\widehat{\boldsymbol{\Theta}}=(\widehat{\lambda}, \widehat{\alpha}, \widehat{k}, \widehat{c})^{T}$. To solve these equations, it is usually more convenient to use nonlinear optimization methods such as the quasi-Newton algorithm to numerically maximize 
$\ell$. The above log-likelihood function also can be maximized numerically by using R (optim), SAS (PROC NLMIXED) or Ox program (sub-routine MaxBFGS), among others.

For interval estimation of the parameters, we obtain the $4 \times 4$ observed information matrix $J_{r s}=J(\boldsymbol{\Theta})=\left\{\frac{\partial^{2} \ell}{\partial r \partial s}\right\}$ (for $r, s=\lambda, \alpha, k, c$ ), whose elements are available upon request from the authors. Its elements also can be computed numerically by the packet program. Under standard regularity conditions when $n \rightarrow \infty$, the distribution of $\widehat{\boldsymbol{\Theta}}$ can be approximated by a multivariate normal $N_{4}\left(0, J(\widehat{\boldsymbol{\Theta}})^{-1}\right)$ distribution to construct approximate confidence intervals for the parameters. Here, $J(\widehat{\boldsymbol{\Theta}})$ is the total observed information matrix evaluated at $\widehat{\boldsymbol{\Theta}}$. Then, approximate $100(1-\delta) \%$ confidence intervals for $\alpha, \lambda, c$ and $k$ can be determined by: $\widehat{\alpha} \pm z_{\delta / 2} \sqrt{\widehat{J}_{\alpha \alpha}^{-1}}, \widehat{\lambda} \pm z_{\delta / 2} \sqrt{\widehat{J}_{\lambda \lambda}^{-1}}$, $\widehat{c} \pm z_{\delta / 2} \sqrt{\widehat{J}_{c c}^{-1}}$ and $\widehat{k} \pm z_{\delta / 2} \sqrt{\widehat{J}_{k k}^{-1}}$, where $z_{\delta / 2}$ is the upper $\delta$ th percentile of the standard normal model and $\widehat{J}_{i i}^{-1}$ are diagonal elements of $J(\widehat{\boldsymbol{\Theta}})^{-1}$ for $i=\alpha, \lambda, c$ and $k$.

\section{Simulation Studies}

In this section, we perform two simulation studies by using the EBXII binomial and EBXII logarithmic distributions to see the performance of MLEs corresponding to these distribution. The random numbers generation is obtained by the inverse of their cdfs. Thus, we use the following steps:

- Generate $u \sim$ uniform $(0,1)$,

- Solve the following nonlinear equation for given parameters values,

$$
F(x ; \boldsymbol{\Theta})=1-C\left[\lambda-\lambda\left[1-\left(1+x^{c}\right)^{-k}\right]^{\alpha}\right] / C(\lambda)-u=0 .
$$

The uniroot routine of the $\mathrm{R}$ packet program can be used to solve the nonlinear equation given in the second item. All results related to MLEs were obtained using the optim-CG routine in the R program.

\subsection{Simulation Study 1}

In the first simulation study, we obtain the graphical results. We generate $n=1000$ samples of size $n=20,25, \ldots, 400$ from EBXII binomial distribution with true parameters' values $\alpha=1.5, \theta=10$, $c=8$ and $k=0.5$. We assume that the parameter $m$, number of replicas, is 3 . In this simulation study, we empirically calculate the mean, standard deviations (SD), bias and mean square error (MSE) of the MLEs. The bias and MSE are calculated by (for $h=\alpha, \theta, c, k$ )

$$
\widehat{\operatorname{Bias}}_{h}=\frac{1}{1000} \sum_{i=1}^{1000}\left(\hat{h}_{i}-h\right),
$$

and

$$
\widehat{M S E}_{h}=\frac{1}{1000} \sum_{i=1}^{1000}\left(\hat{h}_{i}-h\right)^{2},
$$

respectively. We give results of this simulation study in Figure 5. From Figure 5, we observe that, when the sample size increases, the empirical means approach the true parameter value, whereas all biases, SDs and MSEs approach 0 in all cases. 

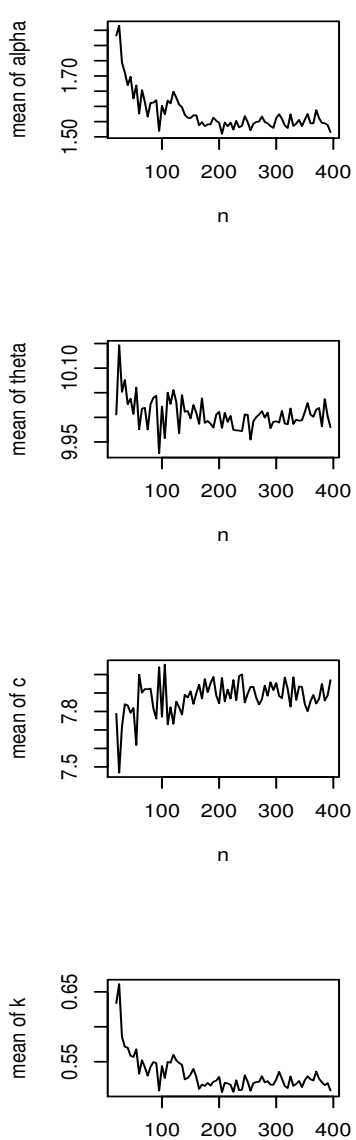

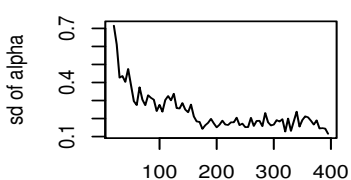

$\mathrm{n}$
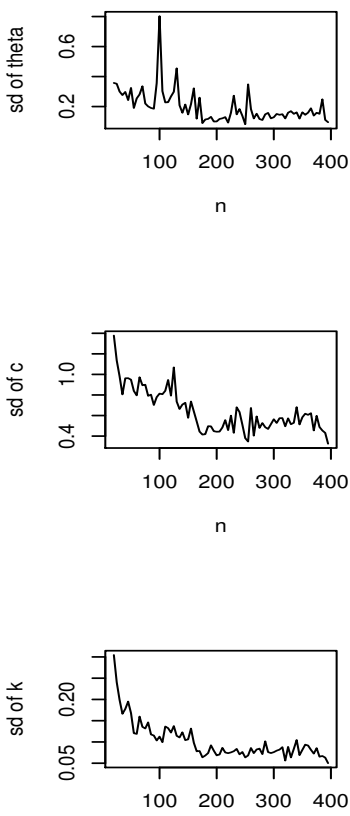

$\mathrm{n}$

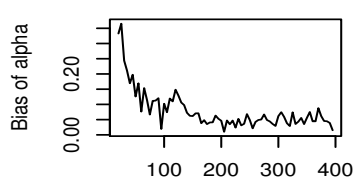

$\mathrm{n}$

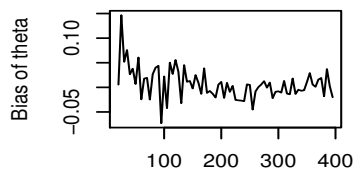

$\mathrm{n}$
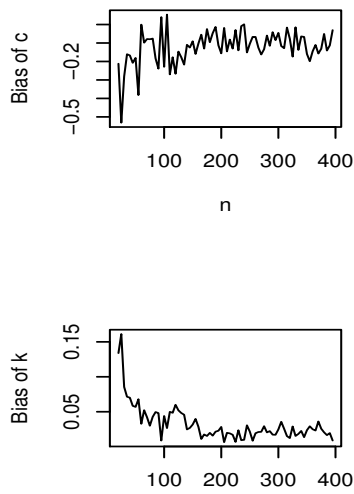
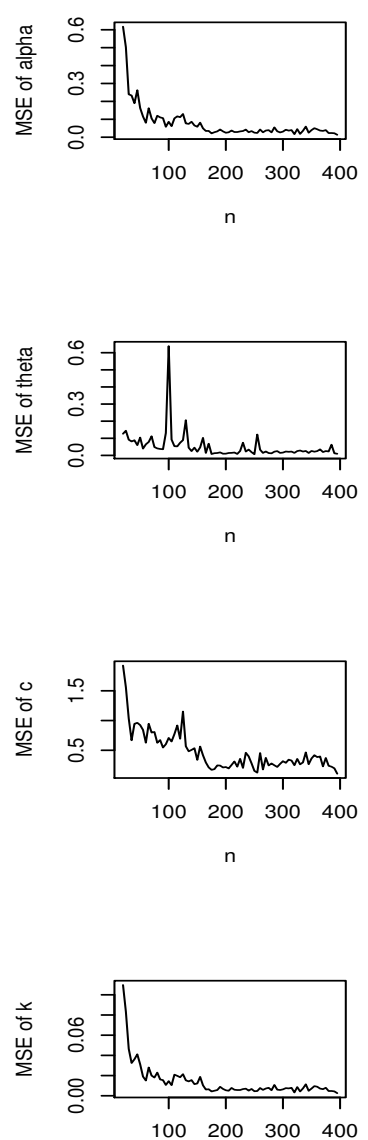

$\mathrm{n}$

$\mathrm{n}$

$\mathrm{n}$

Figure 5. Simulation results of the special EBXII binomial distribution with $m=3$.

\subsection{Simulation Study 2}

In the second simulation study, we generate 1000 samples of sizes 50, 100 and 200 from selected EBXII logarithmic distributions. For this simulation study, we obtain the empirical means and SDs of the MLEs. The results of this simulation study are reported in Table 2. Table 2 shows that, when the sample size increases, the empirical means approach true parameter values, whereas the SDs decrease, as expected.

Table 2. Empirical means and standard deviations (in parentheses) for the special EBXII logarithmic distributions.

\begin{tabular}{|c|c|c|c|c|c|c|c|c|c|c|c|c|}
\hline \multirow{2}{*}{$\begin{array}{c}\text { Parameters } \\
\alpha, c, k, \theta\end{array}$} & \multicolumn{4}{|c|}{$n=50$} & \multicolumn{4}{|c|}{$n=100$} & \multicolumn{4}{|c|}{$n=200$} \\
\hline & $\widehat{\alpha}$ & $\widehat{c}$ & $\widehat{k}$ & $\widehat{\theta}$ & $\widehat{\alpha}$ & $\widehat{c}$ & $\widehat{k}$ & $\widehat{\theta}$ & $\widehat{\alpha}$ & $\widehat{c}$ & $\widehat{k}$ & $\widehat{\theta}$ \\
\hline $2,0.5,0.5,0.5$ & $\begin{array}{c}2.1928 \\
(0.3739)\end{array}$ & $\begin{array}{c}0.5310 \\
(0.1468)\end{array}$ & $\begin{array}{c}0.3114 \\
(0.2383)\end{array}$ & $\begin{array}{c}2.1858 \\
(0.5159)\end{array}$ & $\begin{array}{c}2.1284 \\
(0.2951)\end{array}$ & $\begin{array}{c}0.5115 \\
(0.1055)\end{array}$ & $\begin{array}{c}0.3696 \\
(0.2005)\end{array}$ & $\begin{array}{c}2.0686 \\
(0.4276)\end{array}$ & $\begin{array}{c}2.0594 \\
(0.1405)\end{array}$ & $\begin{array}{c}0.5008 \\
(0.0677)\end{array}$ & $\begin{array}{c}0.4321 \\
(0.1259)\end{array}$ & $\begin{array}{c}2.0351 \\
(0.2414)\end{array}$ \\
\hline $1,0.5,3,0.75$ & $\begin{array}{c}1.0621 \\
(0.4210) \\
\end{array}$ & $\begin{array}{c}0.6203 \\
(0.2078) \\
\end{array}$ & $\begin{array}{c}2.9386 \\
(0.3679) \\
\end{array}$ & $\begin{array}{c}0.6986 \\
(0.3324) \\
\end{array}$ & $\begin{array}{c}1.0569 \\
(0.3474) \\
\end{array}$ & $\begin{array}{c}0.5545 \\
(0.1529) \\
\end{array}$ & $\begin{array}{c}2.9642 \\
(0.2411) \\
\end{array}$ & $\begin{array}{c}0.7734 \\
(0.2188) \\
\end{array}$ & $\begin{array}{c}0.9722 \\
(0.2352) \\
\end{array}$ & $\begin{array}{c}0.5219 \\
(0.0731) \\
\end{array}$ & $\begin{array}{c}2.9723 \\
(0.1793) \\
\end{array}$ & $\begin{array}{c}0.7567 \\
(0.1538) \\
\end{array}$ \\
\hline $3,0.1,3,0.1$ & $\begin{array}{c}2.9904 \\
(0.1310)\end{array}$ & $\begin{array}{c}0.1044 \\
(0.0117)\end{array}$ & $\begin{array}{c}3.0617 \\
(0.1578)\end{array}$ & $\begin{array}{c}0.1154 \\
(0.1754)\end{array}$ & $\begin{array}{c}2.9902 \\
(0.1053)\end{array}$ & $\begin{array}{c}0.1002 \\
(0.0078)\end{array}$ & $\begin{array}{c}2.9978 \\
(0.1181)\end{array}$ & $\begin{array}{c}0.0785 \\
(0.1633)\end{array}$ & $\begin{array}{c}3.0087 \\
(0.0805)\end{array}$ & $\begin{array}{c}0.1005 \\
(0.0053)\end{array}$ & $\begin{array}{c}3.0027 \\
(0.0942)\end{array}$ & $\begin{array}{c}0.1022 \\
(0.1170)\end{array}$ \\
\hline $5,0.9,2,0.9$ & $\begin{array}{c}4.9810 \\
(0.7592) \\
\end{array}$ & $\begin{array}{c}0.9545 \\
(0.1832) \\
\end{array}$ & $\begin{array}{c}2.1140 \\
(0.6073) \\
\end{array}$ & $\begin{array}{c}0.8496 \\
(0.9044) \\
\end{array}$ & $\begin{array}{c}5.0138 \\
(0.2847) \\
\end{array}$ & $\begin{array}{c}0.9169 \\
(0.0882) \\
\end{array}$ & $\begin{array}{c}2.0942 \\
(0.4431) \\
\end{array}$ & $\begin{array}{c}0.8699 \\
(0.4365) \\
\end{array}$ & $\begin{array}{c}4.9976 \\
(0.1819) \\
\end{array}$ & $\begin{array}{c}0.9104 \\
(0.0703) \\
\end{array}$ & $\begin{array}{c}1.9875 \\
(0.2970) \\
\end{array}$ & $\begin{array}{c}0.8711 \\
(0.1816) \\
\end{array}$ \\
\hline $5,5,5,0.99$ & $\begin{array}{c}4.9483 \\
(0.3309) \\
\end{array}$ & $\begin{array}{c}4.9838 \\
(0.2440) \\
\end{array}$ & $\begin{array}{c}5.0854 \\
(0.4827) \\
\end{array}$ & $\begin{array}{c}0.9572 \\
(0.1362) \\
\end{array}$ & $\begin{array}{c}4.9415 \\
(0.3526) \\
\end{array}$ & $\begin{array}{c}5.0126 \\
(0.2423) \\
\end{array}$ & $\begin{array}{c}5.1212 \\
(0.5678) \\
\end{array}$ & $\begin{array}{c}0.9842 \\
(0.1036) \\
\end{array}$ & $\begin{array}{c}4.9743 \\
(0.1308) \\
\end{array}$ & $\begin{array}{c}4.9785 \\
(0.1446) \\
\end{array}$ & $\begin{array}{c}5.0246 \\
(0.2212) \\
\end{array}$ & $\begin{array}{c}0.9954 \\
(0.0209) \\
\end{array}$ \\
\hline $10,0.7,0.5,0.3$ & $\begin{array}{l}10.0795 \\
(0.3178)\end{array}$ & $\begin{array}{c}0.7367 \\
(0.2787)\end{array}$ & $\begin{array}{c}0.4899 \\
(0.1950)\end{array}$ & $\begin{array}{c}0.2615 \\
(0.5675)\end{array}$ & $\begin{array}{l}10.0686 \\
(0.2825)\end{array}$ & $\begin{array}{c}0.7103 \\
(0.2398)\end{array}$ & $\begin{array}{c}0.4901 \\
(0.1558)\end{array}$ & $\begin{array}{c}0.2925 \\
(0.4701)\end{array}$ & $\begin{array}{l}10.0355 \\
(0.1563)\end{array}$ & $\begin{array}{c}0.7077 \\
(0.2049)\end{array}$ & $\begin{array}{c}0.4974 \\
(0.1341)\end{array}$ & $\begin{array}{c}0.3026 \\
(0.2793)\end{array}$ \\
\hline $0.8,2,0.2,0.5$ & $\begin{array}{c}1.0035 \\
(0.3488)\end{array}$ & $\begin{array}{c}1.8689 \\
(0.4761)\end{array}$ & $\begin{array}{c}0.2907 \\
(0.2087)\end{array}$ & $\begin{array}{c}0.4027 \\
(0.4911)\end{array}$ & $\begin{array}{c}0.8862 \\
(0.1938)\end{array}$ & $\begin{array}{c}1.9841 \\
(0.3719)\end{array}$ & $\begin{array}{c}0.2169 \\
(0.0883)\end{array}$ & $\begin{array}{c}0.5169 \\
(0.2861)\end{array}$ & $\begin{array}{c}0.8488 \\
(0.1275)\end{array}$ & $\begin{array}{c}1.9911 \\
(0.2608)\end{array}$ & $\begin{array}{c}0.2104 \\
(0.0616)\end{array}$ & $\begin{array}{c}0.5121 \\
(0.2586)\end{array}$ \\
\hline
\end{tabular}




\section{Data Analysis}

In this section, we provide applications to three real data sets to prove empirically the potentiality of some members of the EBXIIPS distributions. We also compare the fits of these models with Burr XII geometric (BXII-G) model, which is studied by $[14,16]$. To determine the optimum model, we also compute the estimated log-likelihood values $\hat{\ell}$, Akaike Information Criteria (AIC), Kolmogorov-Smirnov (KS), Cramer-von Mises $\left(W^{*}\right)$ and Anderson-Darling $\left(A^{*}\right)$ goodness of-fit statistics for all models. The statistics $W^{*}$ and $A^{*}$ are described in detail in [17]. In general, it can be chosen as the best model which has the smaller values of the AIC, KS, $W^{*}$ and $A^{*}$ statistics and the larger values of $\hat{\ell}$.

All computations of the MLEs are performed by the maxLik routine and all goodness-of-fits statistics are calculated by the goftest routine in the $\mathrm{R}$ program. The details are given by followings.

\subsection{Stress Data}

The first real data set introduces the stress-rupture life of kevlar 49/epoxy strands which are subjected to constant sustained pressure at the $90 \%$ stress level until all had failed such that we obtain complete data with exact failure times. This data set was studied by $[1,18,19]$. The data are: $0.01,0.01$, $0.02,0.02,0.02,0.03,0.03,0.04,0.05,0.06,0.07,0.07,0.08,0.09,0.09,0.1,0.1,0.11,0.11,0.12,0.13,0.18$, $0.19,0.2,0.23,0.24,0.24,0.29,0.34,0.35,0.36,0.38,0.4,0.42,0.43,0.52,0.54,0.56,0.6,0.6,0.63,0.65,0.67$, $0.68,0.72,0.72,0.72,0.73,0.79,0.79,0.8,0.8,0.83,0.85,0.9,0.92,0.95,0.99,1,1.01,1.02,1.03,1.05,1.1$, $1.1,1.11,1.15,1.18,1.2,1.29,1.31,1.33,1.34,1.4,1.43,1.45,1.5,1.51,1.52,1.53,1.54,1.54,1.55,1.58,1.60$, $1.63,1.64,1.8,1.8,1.81,2.02,2.05,2.14,2.17,2.33,3.03,3.03,3.34,4.2,4.69,7.89$.

Table 3 lists the MLEs, their standard errors of the parameters, $\hat{\ell}$ and goodness-of-fits statistics from the fitted models. Table 3 shows that the EBXII-L model could be chosen as the best model among the fitted models since these models have the lowest values of the AIC, KS, $W^{*}$ and $A^{*}$ statistics and have the biggest $\hat{\ell}$ values.

Table 3. MLEs, standard errors of the estimates (in parentheses), $\hat{\ell}$ and goodness-of-fits statistics for the first data set.

\begin{tabular}{cccccccccc}
\hline Model & $\widehat{\boldsymbol{\alpha}}$ & $\widehat{\boldsymbol{\theta}}$ & $\widehat{\boldsymbol{c}}$ & $\widehat{\boldsymbol{k}}$ & $-\hat{\boldsymbol{\ell}}$ & AIC & KS & $A^{*}$ & $\boldsymbol{W}^{*}$ \\
\hline EBXII-G & 0.1837 & -2.3736 & 2.8794 & 0.7734 & 102.2356 & 212.4712 & 0.0835 & 0.8597 & 0.1276 \\
& $(0.0531)$ & $(1.2987)$ & $(0.0852)$ & $(0.0573)$ & & & & & \\
\hline BXII-G & & -6.5779 & 0.7905 & 3.8292 & 103.7589 & 213.5178 & 0.0907 & 1.3308 & 0.1920 \\
& & $(9.3669)$ & $(0.2420)$ & $(1.6013)$ & & & & & \\
\hline EBXII-L & 0.1466 & -16.6902 & 3.5208 & 0.7453 & 101.0149 & 210.0298 & 0.0761 & 0.6064 & 0.0821 \\
& $(0.0244)$ & $(5.1283)$ & $(0.0233)$ & $(0.1067)$ & & & & & \\
\hline EBXII-P & 0.2237 & -1.6098 & 2.8432 & 0.6581 & 103.4967 & 214.9934 & 0.0850 & 1.2765 & 0.2155 \\
& $(0.0592)$ & $(0.8678)$ & $(0.0996)$ & $(0.1445)$ & & & & & \\
\hline BurrXII & & & 1.1736 & 1.6327 & 108.5477 & 221.0955 & 0.1143 & 2.8873 & 0.3072 \\
& & & $(0.0983)$ & $(0.1638)$ \\
\hline
\end{tabular}

The plots of the fitted densities and cdfs are displayed in Figure 6. We also draw probability-probability (P-P) plot of all models in Figure 7. These plots shows that the EBXII-L provides the good fit to these data compared to the other models. 

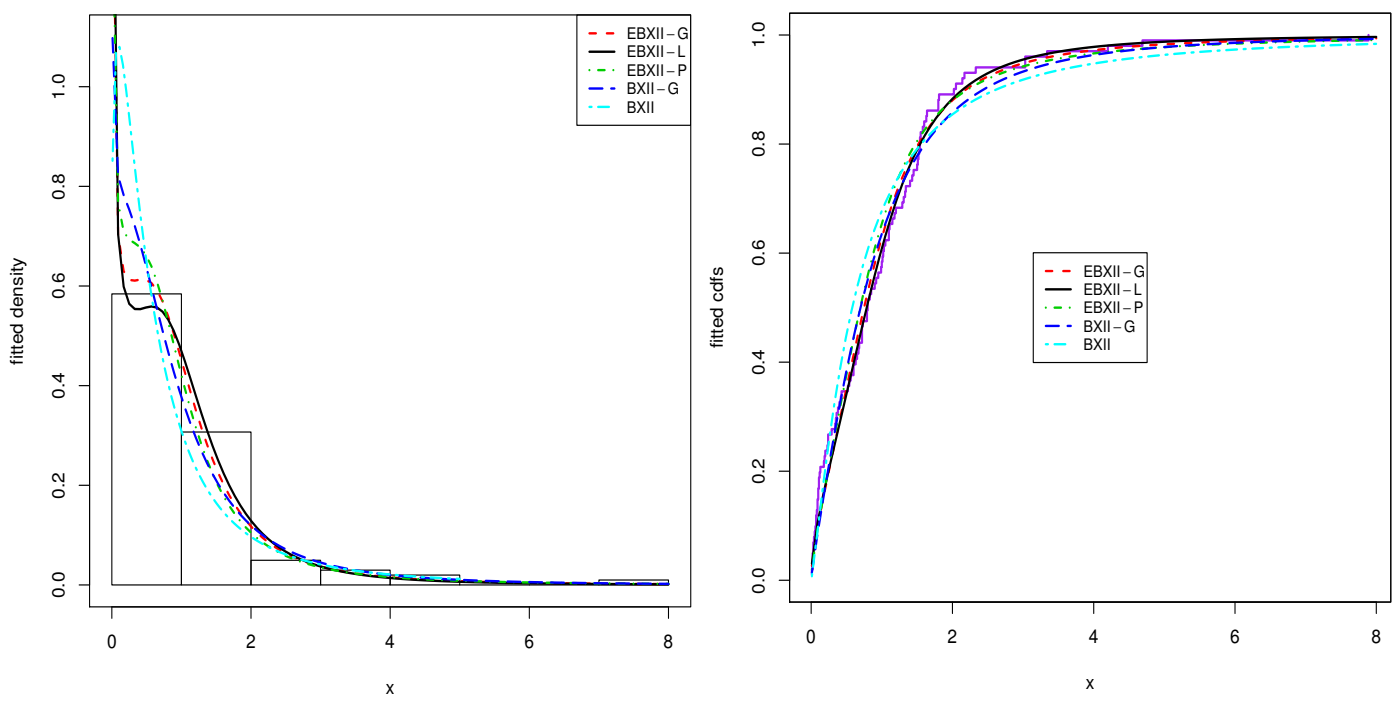

Figure 6. The fitted densities and cdfs for the first data set.
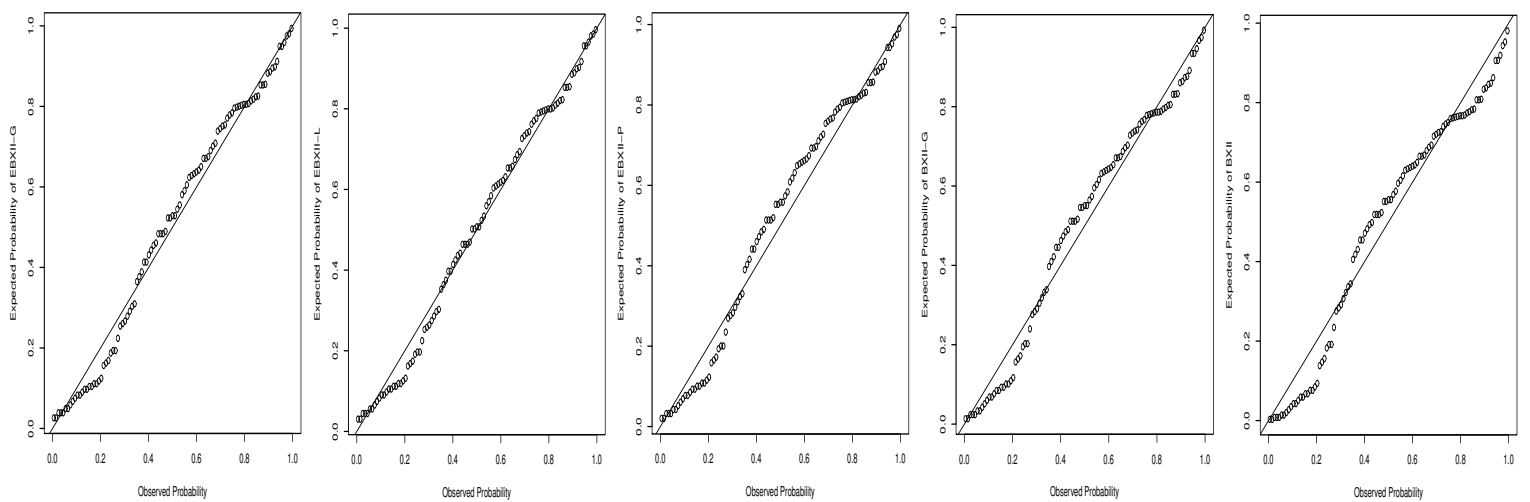

Figure 7. P-P plots of all models for the first data set.

\subsection{Service Times Data}

The second real data set represents the data on service times of 63 aircraft windshield given in [20]. The data are: $0.046,1.436,2.592,0.140,1.492,2.600,0.150,1.580,2.670,0.248,1.719,2.717,0.280,1.794$, $2.819,0.313,1.915,2.820,0.389,1.920,2.878,0.487,1.963,2.950,0.622,1.978,3.003,0.900,2.053,3.102$, $0.952,2.065,3.304,0.996,2.117,3.483,1.003,2.137,3.500,1.010,2.141,3.622,1.085,2.163,3.665,1.092$, $2.183,3.695,1.152,2.240,4.015,1.183,2.341,4.628,1.244,2.435,4.806,1.249,2.464,4.881,1.262,2.543$, 5.140. These data sets were recently studied by [21]. The unit for measurement is $1000 \mathrm{~h}$ for both data sets.

Table 4 lists the MLEs, their standard errors of the parameters, $\hat{\ell}$ and goodness-of-fits statistics from the fitted models. Table 4 shows that the EBXII-L model fits this data set better than the other models according to the statistics $\hat{\ell}$, AIC and $A^{*}$. At the same time, we can say that the data set is better fitted by the EBXII-G according to the statistics $K$ and $W^{*}$.

We draw the fitted densities and cdfs, and the P-P plots in Figures 8 and 9, respectively, for the data set. Clearly, the EBXII-L distribution provides a closer fit to the empirical cdf. From all these results, we may choose the EBXII-L model as the best model for this data set. 
Table 4. MLEs, standard errors of the estimates (in parentheses), $\hat{\ell}$ and goodness-of-fits statistics for the second data set.

\begin{tabular}{|c|c|c|c|c|c|c|c|c|c|}
\hline Model & $\widehat{\alpha}$ & $\widehat{\theta}$ & $\widehat{c}$ & $\widehat{k}$ & $-\hat{\ell}$ & $A I C$ & $K S$ & $A^{*}$ & $W^{*}$ \\
\hline EBXII-G & $\begin{array}{c}0.3573 \\
(0.4481)\end{array}$ & $\begin{array}{c}-69.4175 \\
(7.6873)\end{array}$ & $\begin{array}{l}1.3364 \\
(0.7013)\end{array}$ & $\begin{array}{c}2.6885 \\
(1.7470)\end{array}$ & 102.0361 & 212.0721 & 0.0935 & 0.6693 & 0.0803 \\
\hline BXII-G & & $\begin{array}{c}-47.7605 \\
(4.0336)\end{array}$ & $\begin{array}{c}1.0344 \\
(0.1569)\end{array}$ & $\begin{array}{c}3.6365 \\
(0.3727)\end{array}$ & 102.3057 & 210.6114 & 0.0967 & 0.7748 & 0.0861 \\
\hline EBXII-L & $\begin{array}{c}0.2364 \\
(0.0461)\end{array}$ & $\begin{array}{c}-3.5 \times 10^{6} \\
(0.4027)\end{array}$ & $\begin{array}{c}2.9710 \\
(0.1331)\end{array}$ & $\begin{array}{c}3.0922 \\
(0.1867)\end{array}$ & 99.5671 & 207.1343 & 0.1067 & 0.4639 & 0.0860 \\
\hline EBXII-P & $\begin{array}{c}1.0879 \\
(0.6565)\end{array}$ & $\begin{array}{r}-3.6258 \\
(1.1587)\end{array}$ & $\begin{array}{c}1.4626 \\
(0.4915)\end{array}$ & $\begin{array}{c}1.5307 \\
(0.6687)\end{array}$ & 108.0832 & 224.1664 & 0.1498 & 1.7402 & 0.2545 \\
\hline BurrXII & & & $\begin{array}{c}2.1335 \\
(0.2804)\end{array}$ & $\begin{array}{c}0.6151 \\
(0.0982)\end{array}$ & 116.1148 & 236.2296 & 0.2545 & 10.4160 & 1.3521 \\
\hline
\end{tabular}

The plots of the fitted densities and cdfs are displayed in Figure 8. We also draw P-P plot of all models in Figure 9. These plots shows that the EBXII-L provides the good fit to these data compared to the other models.
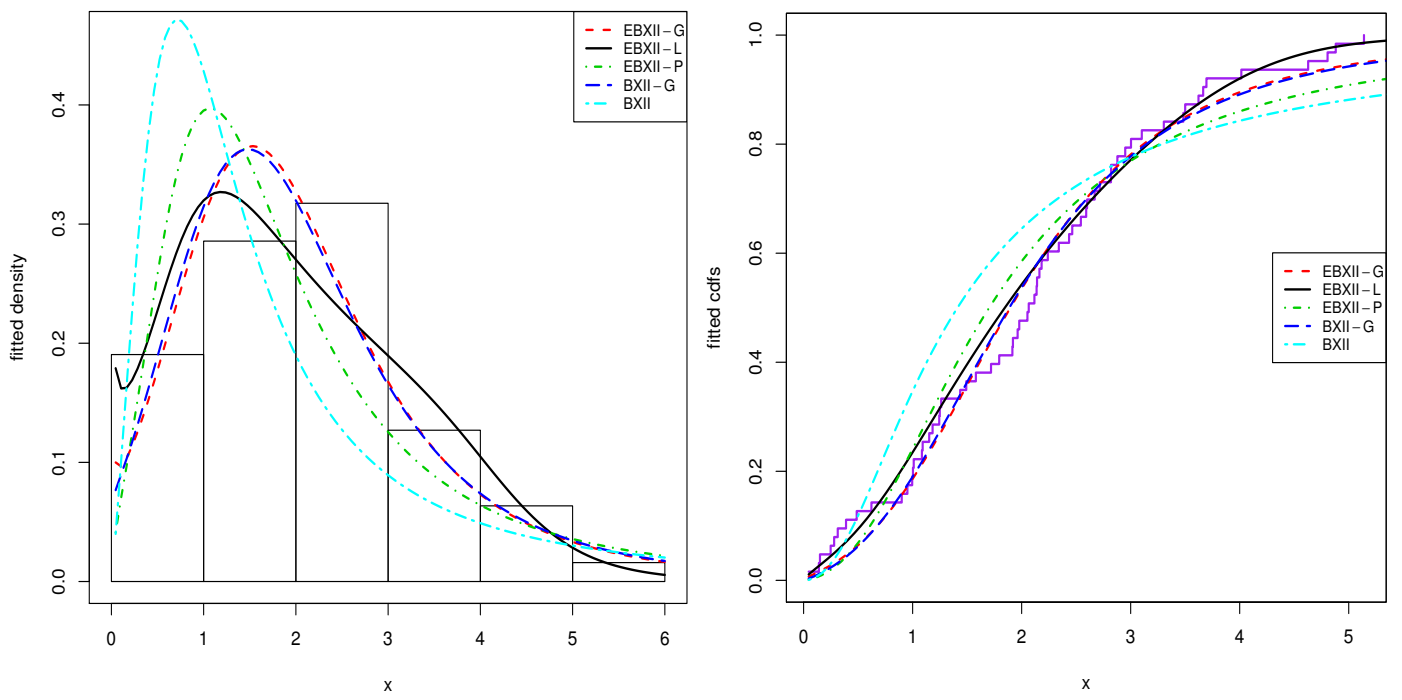

Figure 8. The fitted densities and cdfs for the second data set.
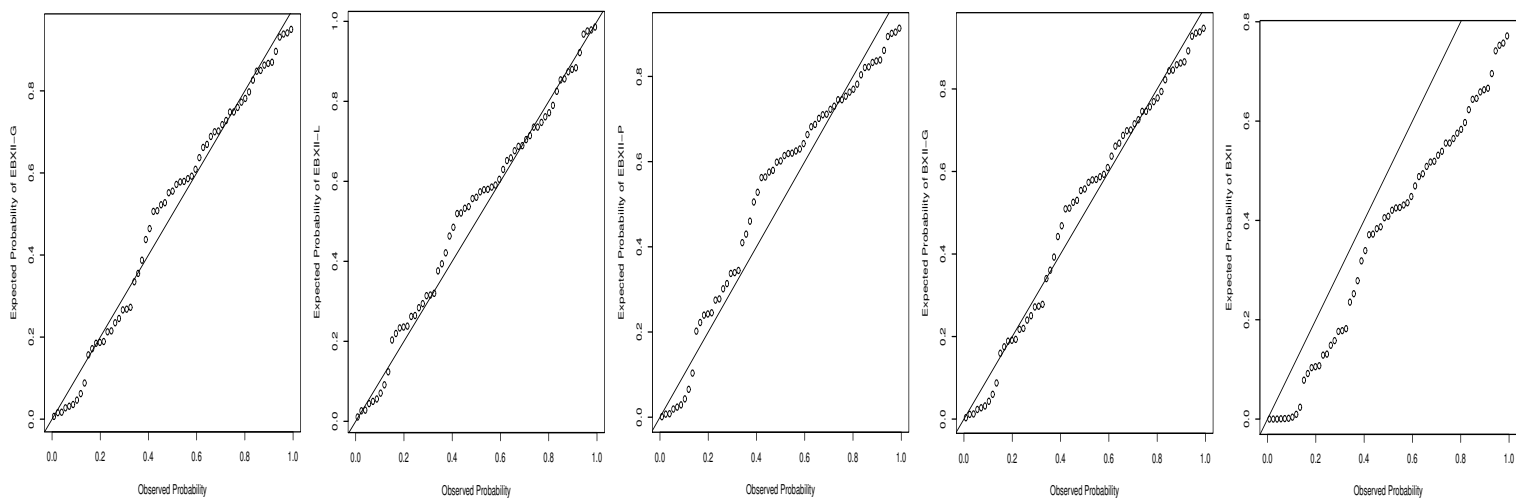

Figure 9. P-P plots of all models for the second data set. 


\subsection{Failure Data}

The third real data consists of the number of successive failures for the air conditioning systems reported for each member in a fleet of 13 Boeing 720 jet airplanes. The pooled data with 213 observations was considered by [22,23].

Table 5 lists the MLEs, their standard errors of the parameters, $\hat{\ell}$ and goodness-of-fits statistics from the fitted models. Table 5 shows that the EBXII-G model fits this data set better than the other models according to the statistics $\hat{\ell}$, AIC and $A^{*}$.

We draw the fitted densities and cdfs, and the P-P plots in Figures 10 and 11, respectively, for the data set. Clearly, the EBXII-G distribution provides a closer fit to the empirical cdf. From all these results, we may choose the EBXII-G model as the best model for this data set.

Table 5. MLEs, standard errors of the estimates (in parentheses), $\hat{\ell}$ and goodness-of-fits statistics for the third data set.

\begin{tabular}{cccccccccc}
\hline Model & $\widehat{\boldsymbol{\alpha}}$ & $\widehat{\boldsymbol{\theta}}$ & $\widehat{\boldsymbol{c}}$ & $\widehat{\boldsymbol{k}}$ & $-\hat{\ell}$ & $A I C$ & $K S$ & $A^{*}$ & $W^{*}$ \\
\hline EBXII-G & 324.1786 & -59.7180 & 0.2562 & 7.4612 & 1178.5170 & 2365.0330 & 0.0410 & 0.5110 & 0.0592 \\
& $(0.5597)$ & $(0.1066)$ & $(0.0085)$ & $(0.1257)$ & & & & & \\
\hline BXII-G & & -349.9338 & 0.8401 & 1.7449 & 1180.261 & 2366.5210 & 0.0413 & 0.5832 & 0.0678 \\
& & $(1.2261)$ & $(0.2915)$ & $(0.5884)$ & & & & & \\
\hline EBXII-L & 377.6428 & -267.0753 & 0.3544 & 5.6072 & 1189.0280 & 2386.0560 & 0.1026 & 3.9962 & 0.7387 \\
& $(0.1188)$ & $(0.1809)$ & $(0.0226)$ & $(0.2711)$ & & & & & \\
\hline EBXII-P & 68.2377 & -4.1156 & 0.3268 & 3.9270 & 1186.3710 & 2380.7430 & 0.0645 & 1.4650 & 0.1768 \\
& $(2.2356)$ & $(0.9638)$ & $(0.0319)$ & $(0.3690)$ & & & & & \\
\hline \multirow{2}{*}{ BurrXII } & & 53.7460 & 0.0047 & 1335.4150 & 2674.8300 & 0.3697 & 44.8020 & 9.2016 \\
& & $(1.6200)$ & $(0.0004)$ & & & & & \\
\hline
\end{tabular}
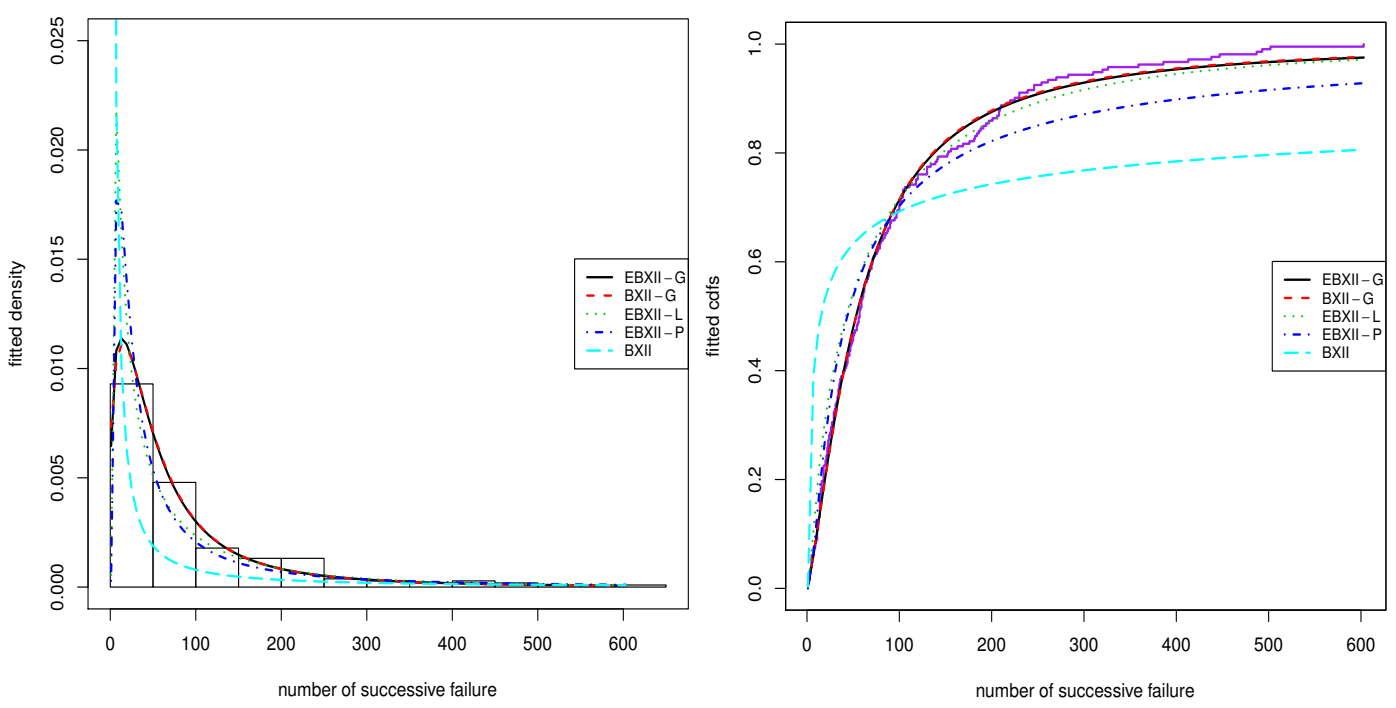

Figure 10. The fitted densities and cdfs for the third data set. 

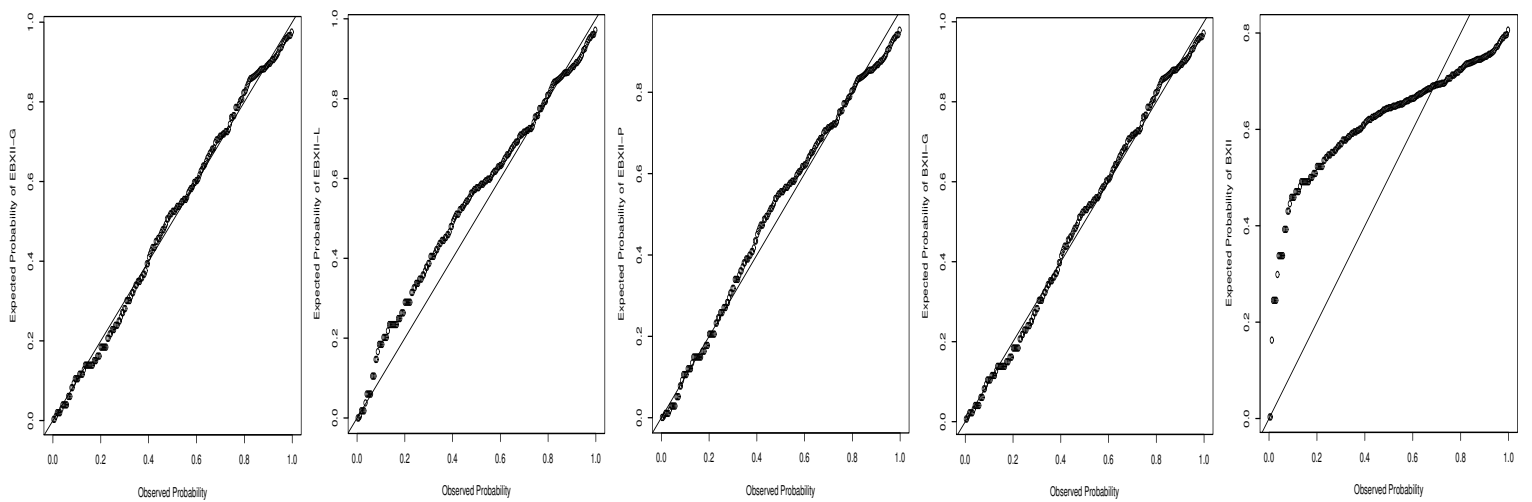

Figure 11. P-P plots of all models for the third data set.

\section{Conclusions}

In this work, we introduce a new Burr XII power series class of distributions, which is obtained by compounding Burr XII and power series distributions and has a strong physical motivation. The new distribution contains several important lifetime models. We derive explicit expressions for the ordinary and incomplete moments and generating functions. We discuss the maximum likelihood estimation of the model parameters. The maximum likelihood estimation procedure is presented. We assess the performance of the maximum likelihood estimators in terms of biases, variances, and mean square of errors by means of two simulation studies. The usefulness of the new models is illustrated by means of three real data sets. The new models provide consistently better fits than other competitive models for these data sets.

Author Contributions: methodology and calculations, A.N., F.J. and H.M.Y.; software, writing-review and editing, writing—original draft preparation, M.Ç.K.

Funding: This research received no external funding.

Conflicts of Interest: The authors declare no conflict of interest.

\section{References}

1. Paranaiba, P.F.; Ortega, E.M.; Cordeiro, G.M.; Pascoa, M.A.D. The Kumaraswamy Burr XII distribution: Theory and practice. J. Stat. Comput. Simul. 2013, 83, 2117-2143. [CrossRef]

2. Al-Saiari, A.Y.; Baharith, L.A.; Mousa, S.A. Marshall-Olkin extended Burr type XII distribution. Int. J. Stat. Probab. 2014, 3, 78-84. [CrossRef]

3. Gomes AE da-Silva, C.Q.; Cordeiro, G.M. Two extended Burr models: Theory and practice. Commun. Stat. Theory Methods 2015, 44, 1706-1734. [CrossRef]

4. Arslan, A.M.; Tahir, M.H.; Jamal, F.; Ozel, G. A New Generalized Burr Family of Distributions for the Lifetime Data. J. Stat. Appl. Probab. 2017, 6, 401-417.

5. Johnson, N.L.; Kotz, S.; Balakrishnan, N. Continuous Univariate Distributions, 2nd ed.; Jonh Wiley \& Sons: New York, NY, USA, 1995; Volume 2.

6. Garcia, A.; Torres, J.L.; Prieto, E.; De Francisco, A. Fitting wind speed distributions: A case study. Sol. Energy 1998, 62, 139-144. [CrossRef]

7. Harris, R.I. Generalised Pareto methods for wind extremes. Useful tool or mathematical mirage. J. Wind Eng. Ind. Aerodyn. 2005, 93, 341-360. [CrossRef]

8. Kantar, Y.M.; Usta, I. Analysis of Wind Speed Distribution. Energy Convers. Manag. 2008, 49, 962-973. [CrossRef]

9. Carta, J.A.; Ramirez, P.; Velazquez, S. A review of wind speed probability distributions used in wind energy analysis. Renew. Sustain. Energy Rev. 2009, 13, 933-955. [CrossRef]

10. Panteli, A.T.M.; Mancarella, P. Influence of extreme weather and climate change on the resilience of power systems: Impacts and possible mitigation strategies. Electr. Power Syst. Res. 2015, 127, 259-270. [CrossRef] 
11. Chiodo, E.; De Falco, P. The Inverse Burr Distribution for Extreme Wind Speed Prediction: Genesis, Identification and Estimation. Electr. Power Syst. Res. 2016, 141, 549-561. [CrossRef]

12. Feijóo, D.V. Assessing wind speed simulation methods. Renew. Sustain. Energy Rev. 2016, 56, 473-483. [CrossRef]

13. Noack, A. A Class of Random Variables with Discrete Distributions. Ann. Math. Stat. 1950, 21, 127-132. [CrossRef]

14. Silva, R.B.; Cordeiro, G.M. The Burr XII power series distributions: A new compounding family. Braz. J. Probab. Stat. 2015, 29, 565-589. [CrossRef]

15. Da Silva, R.V.; Gomes-Silva, F.; Ramos, M.W.A.; Cordeiro, G. The exponentiated Burr XII Poisson distribution with application to lifetime data. Int. J. Stat. Probab. 2015, 4, 112-131. [CrossRef]

16. Korkmaz, M.Ç.; Erişoğlu, M. The Burr XII-Geometric Distribution. J. Selcuk Univ. Nat. Appl. Sci. 2014, 3, 75-87.

17. Chen, G.; Balakrishnan, N. A general purpose approximate goodness-of-fit test. J. Qual. Technol. 1995, $27,154-161$.

18. Andrews, D.F.; Herzberg, A.M. Data: A Collection of Problems from Many Fields for the Student and Research Worker; Springer Series in Statistics: New York, NY, USA, 1985.

19. Cooray, K.; Ananda, M.M. A generalization of the half-normal distribution with applications to lifetime data. Commun. Stat. Theory Methods 2008, 37, 1323-1337. [CrossRef]

20. Murthy, D.P.; Xie, M.; Jiang, R. Weibull Models; John Wiley \& Sons: Haboken, NJ, USA, 2004.

21. Tahir, M.H.; Cordeiro, G.M.; Mansoor, M.; Zubair, M. The Weibull-Lomax distribution: Properties and applications. Hacet. J. Math. Stat. 2015, 44, 461-480. [CrossRef]

22. Proschan, F. Theoretical explanation of observed decreasing failure rate. Technometrics 1963, 5, 375-383. [CrossRef]

23. Kuş, C. A new lifetime distribution. Comput. Stat. Data Anal. 2007, 51, 4497-4509. [CrossRef]

(C) 2018 by the authors. Licensee MDPI, Basel, Switzerland. This article is an open access article distributed under the terms and conditions of the Creative Commons Attribution (CC BY) license (http:/ / creativecommons.org/licenses/by/4.0/). 